\title{
Wind and Geothermal Energy in Desalination: A Short Review on Progress and Sustainable Commercial Processes
}

\author{
Abusharkh AG, Giwa A and Hasan SW* \\ Department of Chemical and Environmental Engineering, Masdar Institute of Science and Technology, P.O. Box 54224, Abu Dhabi, United Arab Emirates
}

\begin{abstract}
Fossil fuels have been used as the main energy source for the desalination technologies. The continued increase in the demand for desalinated water has resulted in rising greenhouse gas emissions and threat to available fuel reserves. Consequently, most commercial desalination processes powered by fossil fuels have significantly contributed to environmental pollution. Renewable energy comes into the picture as an environmental friendly option as well as a means of fossil energy minimization. In this paper, a review on the use of renewable energy in recent desalination processes has been carried, with a focus on wind and geothermal energy.
\end{abstract}

Keywords: Renewable energy; Desalination; Wind; Geothermal; Sustainability

\section{Introduction}

About $97 \%$ of the earth's water is saline water that is present in oceans and the remaining $3 \%$ is fresh water present in rivers, lakes and groundwater [1]. The fact that the sustainability of mankind depends on the existence and use of water puts a huge demand on the water from oceans that is considered an inexhaustible source. However, due its high salinity, water from seas and oceans cannot be used directly. This is where desalination becomes the key factor of supplying water suitable for human use by converting the saline water to fresh water [2-4]. Additionally, according to the World Water Council, the world would be about $17 \%$ short of fresh water by 2020 [5]. Desalination plants are increasing annually on a large scale and desalination technologies are usually implemented in coastal and arid areas that have access to seawater sources but lack surface water sources $[1,6]$. However, the production of freshwater from desalination processes requires huge amounts of energy through the combustion of fossil fuels. Therefore, fresh water and energy are considered inseparable commodities essential for the sustenance of human life [7]. As a matter of fact, supplying fresh water without energy is almost impossible because even low-salinity groundwater needs to be pumped before it can be accessible $[8,9]$. Moreover, the rapid growth of the world's population has caused a drastic increase in the rate of depletion of fossils fuels and emission of greenhouse gases [1]. Treated wastewater seems to require less energy and provide renewable options [1012]. Product water of better quality and other useful resources have been obtained from newer wastewater treatment methods including hybridized technology [13-15]. However, the application of treated wastewater for potable uses remains questionable and studies have only focused on reclamation of wastewater for non-potable reuse $[16,17]$.

Now, the issue is: can we continue to afford the depletion of the natural energy sources, the oil expenses, and the harmful greenhouse gas emissions associated with oil combustion for energy generation? Fossil fuel reserves are continually being used for desalination processes because they are more cost-competitive [18]. This calls for the need to develop alternative energy sources for desalination technologies such as renewable and sustainable energy so that the freshwater demand for future generations can be met [19]. This paper reviews the possible renewable energy sources that can be integrated with desalination technologies to reduce the existing stress on water and energy as well as lessen the adverse impacts of desalination on the environment. Since solar desalination has been widely developed and improved in recent years, only the applications of wind and geothermal sources of energy have been reviewed in this paper.

\section{Utilizing Renewable Energy Sources for Desalination}

The selection of a suitable desalination technology driven by wind or geothermal energy depends on the size of the desalination plant, quality of the product water, remoteness of site location, costs of water produced, and availability of the renewable energy source $[18,19]$. Additionally, the characteristics of the feed water to be desalinated must be considered when selecting the renewable energy technology to be implemented. For example, desalinating brackish water will require less energy than sea water because brackish water is less saline. Table 1 provides an evaluation of the renewable energy technologies based on several criteria.

\section{Wind energy}

In areas ambient with wind, wind energy can be converted to wind power to generate electricity. Wind energy can utilize mechanical power to pump water and can be used for drainage purposes [19]. The generation of wind power might involve the construction of a wind farm consisting of a large number of wind turbines that are eventually connected to the electric power transmission network. The use of wind turbines for desalination in coastal areas, with sufficient wind resource, has proven to be an economically feasible desalination method $[20,21]$. Nowadays, some wind farms have been connected with reverse osmosis (RO) desalination plants to provide water in small remote communities that have sufficient wind energy, as they have the least energy requirements $[1,6,9,19,21,22]$. Table 2 presents several existing wind/RO installations.

*Corresponding author: Hasan SW, Department of Chemical and Environmental Engineering, Masdar Institute of Science and Technology, P.O. Box 54224, Abu Dhabi, United Arab Emirates, Tel: 9712810 9237; E-mail: swajih@masdar.ac.ae

Received September 09, 2015; Accepted September 21, 2015; Published September 23, 2015

Citation: Abusharkh AG, Giwa A, Hasan SW (2015) Wind and Geotherma Energy in Desalination: A Short Review on Progress and Sustainable Commercial Processes. Ind Eng Manage 4: 175. doi:10.4172/2169-0316.1000175

Copyright: (C) 2015 Abusharkh AG, et al. This is an open-access article distributed under the terms of the Creative Commons Attribution License, which permits unrestricted use, distribution, and reproduction in any medium, provided the original author and source are credited. 


\begin{tabular}{|c|c|c|c|c|}
\hline Criterion & Solar thermal energy & PV & Wind energy & Geothermal energy \\
\hline $\begin{array}{l}\text { Suitability for powering } \\
\text { desalination plants }\end{array}$ & $\begin{array}{l}\text { Well suited for desalination } \\
\text { plants requiring thermal power }\end{array}$ & $\begin{array}{c}\text { Well suited for desalination } \\
\text { plants requiring electrical power }\end{array}$ & $\begin{array}{l}\text { Well suited for desalination } \\
\text { plants requiring electrical power }\end{array}$ & $\begin{array}{l}\text { Well suited for desalination } \\
\text { plants requiring thermal power }\end{array}$ \\
\hline $\begin{array}{l}\text { Site requirements and } \\
\text { resource availability }\end{array}$ & $\begin{array}{l}\text { Typically good match with need } \\
\text { for desalination }\end{array}$ & $\begin{array}{l}\text { Typically good match with need } \\
\text { for desalination }\end{array}$ & Resource is location-dependent & $\begin{array}{l}\text { Resource is limited to certain } \\
\text { locations }\end{array}$ \\
\hline Continuity of power output & $\begin{array}{l}\text { Output is intermittent (energy } \\
\text { storage required) }\end{array}$ & $\begin{array}{l}\text { Output is intermittent (energy } \\
\text { storage required) }\end{array}$ & $\begin{array}{l}\text { Output is intermittent (energy } \\
\text { storage required) }\end{array}$ & Continuous power output \\
\hline Predictability of power output & Output is relatively unpredictable & Output is relatively unpredictable & Output is very unpredictable & Output is relatively unpredictable \\
\hline
\end{tabular}

Table 1: Evaluation of renewable energy technologies [18].

\begin{tabular}{|c|c|c|c|c|}
\hline Plant location & Year of commission & Water type* & Capacity (L/h) & W/T nominal power (kW) \\
\hline lle de Planier, France & 1983 & SW/BW & 500 & 4 \\
\hline Fuerteventura island, PUNTA JANDIA Project & 1995 & SW & 2333 & 225 \\
\hline Therasia island, Greece & 1997 & SW & 200 & 15 \\
\hline $\begin{array}{l}\text { Pozo Izquierdo, Gan Canaria, AEROGEDESA } \\
\text { Project }\end{array}$ & 2003 & SW & 800 & 15 \\
\hline CREST, UK & 2004 & SW & 500 & 2.5 \\
\hline
\end{tabular}

*SW - seawater; BW - brackish water

Table 2: Existing RO plants powered by wind energy.

Like other energy sources, wind power has several impacts and challenges. However, it is considered to be the least problematic when taking into account the impact on the environment [19]. Additionally, it is becoming more common to use energy from wind in many areas to provide a significant portion of the demand for electricity, hence providing a great potential to be utilized in desalination. The challenges associated with the use of wind power are the intermittency and the fluctuations of the wind resource. However, with advances in research and technology, these challenges can be tackled. For instance, the intermittence in wind energy production can be resolved by combining wind energy with another form of renewable energy to provide a steady operating condition [1]. A considerable number of Wind/RO systems have been designed and tested in different parts of the world. For example, Kwinana desalination plant located in Australia utilizes RO technology powered by wind energy that comes from a wind farm consisting of 48 wind turbines [19]. This plant was very successful as that area encountered a decrease in rainfall but was required to provide freshwater. The wind power from the farm, fed into the power distribution network, was more than enough to run the desalination plant. The plant produces $140 \mathrm{ML}$ drinking water per day; water that is enough to cater for the needs of the area [23].

Some evaluations of the economic feasibility of wind-powered RO plants have also been carried out, taking into account the intermittence, feed pressure, wind availability and speed. These feasibility studies have proved that wind-powered desalination is a successful technique $[5,6]$. Furthermore, the capital cost of the wind-powered RO plant can be reduced by using lighter wind blades, making it more feasible economically [22]. A case study has been carried out in Ténès, Algeria, to analyze the environmental impact of integrating wind energy in seawater RO desalination (SWRO) [23]. The energy yield and economic feasibility of a hypothetical farm consisting of 5 wind turbines were also obtained in this study. The study was projected for 25 years to analyze the reduction of greenhouse gases emissions. It was concluded that 8558.46 tons of greenhouse gases per year can be prevented from being emitted into the atmosphere. Wind energy has also been integrated with Mechanical Vapor Compression (MVC) desalination plants. In fact, a plant existing on Borkum Island, Germany, has a MVC unit with a $60 \mathrm{~kW}$ wind turbine producing distillate at $0.3-2 \mathrm{~m}^{3} / \mathrm{h}[1]$. Whereas, on the Island of Rugen in Baltic Sea, the distillate production varied between $2-15 \mathrm{~m}^{3} / \mathrm{h}$ depending on the wind conditions. In both systems, a variable speed compressor and a resistive heating element were installed to allow for variable power to be absorbed by the units. The advantages of this technique include: the requirement of only wind energy for operation, low process temperature, low energy demand due to efficient heat recovery, and variable rotor speed for higher energy gains [1].

Another example of wind energy coupled with thermal energy is wind generator/photovoltaic energy system implemented to run desalination plants with the presence of a battery bank system [24]. Figure 1 below represents a simple illustration of how wind and photovoltaic energy sources have been integrated in a RO plant.

The energy generated from the wind generators and photovoltaic arrays charges the battery chargers, which in turn charges the battery bank. The role of the battery tank is to supply energy in case of low solar radiation and/or wind speed conditions [9]. The electrical energy stored in the battery bank, DC, passes through that DC/AC converter to be converted to AC to meet the $\mathrm{RO}$ units' requirements. The energy is then supplied to the units to desalinate the water that is fed into the plant, and pump the potable water to be delivered and stored in a water tank. Of course, the reliability of such a system depends on the proper design and size of the desalination plant. A major advantage of this system is that water can be produced when the power supply is sufficient and at the same time, stored to be used when the power drops, saving expenses of having a back-up system [1].

\section{Wind/gravitational potential energy}

In other cases, gravitational potential energy has been used as an interface between wind energy and desalination processes $[25,26]$. This concept involves the design of a RO desalination system model that incorporates gravitational potential energy with wind energy [27]. In a typical RO plant, a high pressure pump is required to pump the feed seawater through membranes so that the feed water can be separated into pure water and brine solution. The alternative solution proposed was a special piston inside desalination columns that can be used to produce enough pressure to achieve a flux at the inlet of the membranes, instead of using the high pressure pump that requires energy. This arrangement consisted of two desalination columns acting as individual pumps connected through an automatic hydraulic system. The automatic hydraulic system provides a continuous flow of the saline water into the membranes. The energy required comes from the wind mill and is converted to gravitational potential. In turn, the 


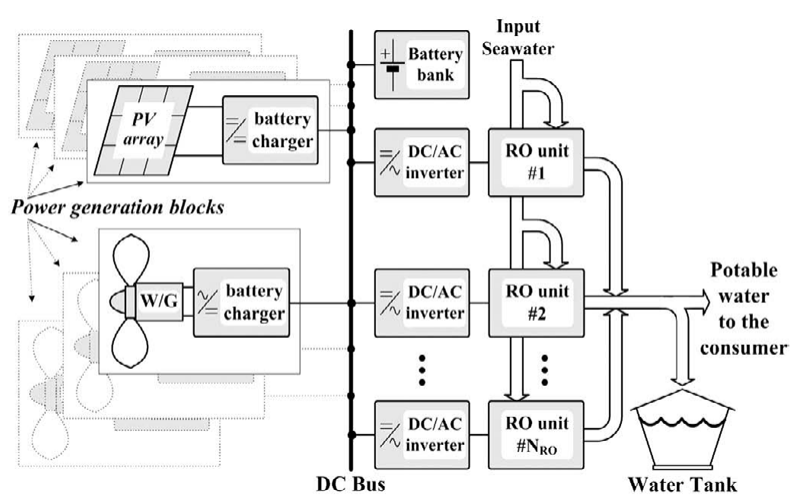

Figure 1: Configuration of RO plant powered by wind and photovoltaic energy sources [25].

feed saline water will be pumped through the membranes with the least energy consumption. The main advantages of this proposed model include: economic viability, because of the use of a free renewable source of energy; reduction of emissions of carbon dioxide into the atmosphere; low specific energy consumption; and simplicity of the system, and therefore low maintenance costs.

\section{Geothermal energy}

Geothermal energy is another renewable technology that can be used to produce electricity in desalination plants. Although it is not spread out commercially, it is an appealing solution for water scarcity and it saves fossils fuels. The use of geothermal energy in desalination plants has several advantages [1]. It is environmentally friendly, with no emissions of air pollutants and greenhouse gases. This method provides a stable and reliable heat supply suitable for thermal desalination and RO [28]. It saves fossil fuels so they can be utilized for other purposes and it is a mature technology that is cost effective. Some geothermalpowered thermal desalination units exist, with sizes ranging from small to middle-sized units. In Mexico, a country with an extensive geothermal resource and geothermal water at $80^{\circ} \mathrm{C}$, the options for geothermal seawater desalination by multi-stage flash (MSF) and multi-effect distillation (MED) have been evaluated [29]. A laboratory test was conducted and a prototype geothermal desalination unit was designed. It was found that $118 \mathrm{~m}^{3}$ of geothermal water at $80^{\circ} \mathrm{C}$ was able to desalinate $20 \mathrm{~m}^{3} /$ day of seawater [28]. Basically, geothermal hot water was used as an energy source to preheat the feed seawater to its boiling point and evaporate it to separate it from the salt, avoiding the use of steam as an energy source as well as decreasing the cost of desalinated water. This system is called Low Energy-Multi Effect Distillation (LEMED) that avoids the use of fossil fuel to generate steam. Additionally, economic analysis of the system was carried out and the results proved that the cost per cubic meter of desalinated water has been reduced by $30 \%$ with the use of geothermal energy [29].

The fact that geothermal energy provides a stable source of energy makes it more favorable than solar energy for desalination. In solarpowered desalination plants, often a thermal energy storage system is developed for night time operation and cloudy days. However, by integrating geothermal energy with solar-powered desalination plants, thermal energy storage can be eliminated and desalination plants can be operated continuously [28]. Geothermal water can serve as energy feed for a desalination plant as well as a heat transfer medium for desalination [1]. Furthermore, an important parameter responsible for the efficiency of a geothermal-powered desalination plant is the geothermal temperature. It is possible to regulate the desalinated flow rate by managing the geothermal temperature [30]. In Pantelleria, a small volcanic island in Italy that is located among major tectonic plates and possesses a significant geothermal resource, a MED plant powered by geothermal energy has been designed to produce fresh water and handle water shortage. The layout of the proposed desalination process consists of the following sections: Geothermal loop, multiple effects evaporators, seawater heat integration, collection of desalinated water, pumps for desalinated and brine water. The system is an amalgamation of several innovations that have been simulated to analyze the effect of implementing it in the island. For instance, the closed geothermal loop allows for the reuse of geothermal heat, thereby reducing the drilling cost for geothermal heat extractions. Additionally, using desalinated water in the geothermal well prevents corrosion issues [30]. It has been observed that the integration of geothermal energy in the island is an appealing solution because: the cost of fresh water was reduced, the desalination process was completely sustainable, and variable costs were found to be quite low in the long run.

\section{Conclusions}

In contrast to well-established renewable energy sources such as solar energy and hydropower, wind and geothermal resources can be described as emerging renewable energy sources because their application, particularly for desalination, is still evolving. However, from this mini review, it can be concluded that wind and geothermal energy sources can provide environmentally friendly and economically viable means of desalinating saline water, most especially in areas with abundant availability of wind and geothermal resources. Feasible pure water production from desalination plants powered with wind and geothermal energy has already been achieved. For example, Kwinana RO desalination plant coupled with wind energy in Australia is capable of producing $140 \mathrm{ML}$ per day of drinking water. This plant is also able to prevent the emission of $8,558.46$ tons of greenhouse gases to the atmosphere every year [23]. Also, the desalination of 20 $\mathrm{m}^{3} / \mathrm{d}$ of seawater has been achieved using geothermal heat source at $80^{\circ} \mathrm{C}$ in Mexico [28]. These examples, among others, have been able to prove that wind and geothermal energy can be used practically in desalination plants. On the economic side, it can be concluded that wind and geothermal energy can reduce the cost of desalination and ensure efficient use of energy for desalination in a sustainable manner. For example, geothermal energy can reduce the specific cost of desalination by $30 \%$. Surely, this is a significant reduction in cost and a considerable enhancement of the economic sustainability of potable water production [28]. However, it is worth noting that the use of wind and geothermal resources is limited by geographical factors, as these resources can only be used effectively in locations where they are surplus and can be practically exploited for energy generation. The suitability of locating desalination plants in these locations and/or the feasibility of transmitting energy generated from wind and geothermal resources to desalination plants are important factors to consider while designing desalination systems that would be powered by these resources. Meanwhile, wind and geothermal energy would be crucial for the construction of many desalination systems in the future because they can be used to produce inexpensive drinking water, even when compared with other renewable energy sources such as hydropower and solar energy.

\section{Future Research Directions}

Although wind energy is considered to be the most environmentally friendly renewable energy, problems might still 
arise from the application of wind energy for desalination because of the intermittency of wind speed [19]. Such fluctuations would lead to variations in the renewable energy generated and inability to accurately predict the specific cost of production of potable water. However, the hybridization of wind energy with other energy sources to stabilize the power output has been considered in some cases [1]. Further research and development activities in this area are highly recommended so that the limitation of wind resource exploitation due to natural factors can be minimized. The design of renewable energy farm and desalination plant is also another important factor that determines the efficiency of wind power as an energy source for desalination. For example, significant reduction in capital costs can be achieved by using lighter but stronger wind blades. Also, the reuse of waste geothermal heat in a closed loop arrangement would reduce the cost of fresh extraction of geothermal energy. In addition, the ability to reuse or recycle the residual energy in all outputs from desalination plants would go a long way in minimizing the energy and cost requirement of these plants. Future research needs to be focused on adequate designs of wind and geothermal desalination plants to avoid energy loopholes or unnecessary energy sinks and ensure optimum efficiency during the consumption of the energy generated.

The focus of this study is not to project wind and geothermal energy as the best or most applicable renewable energy types for desalination, as the renewable energy required to meet the needs of a particular desalination plant would depend on the peculiarities associated with the plant site and operating conditions. It is not a rule of thumb that wind and geothermal energy would give the optimal results for every desalination activity and sometimes, they might not be self-sufficient. Rather, this short review has been able to show that wind and geothermal energy can be integrated with other energy sources to improve the economics and reduce the environmental impacts of desalination process. The coupling of wind energy with thermal and photovoltaic energy systems and the use of wind energy to supply gravitational potential energy required for desalination have yielded impressive results. The major benefit of coupled systems is that all-round power supply can be achieved and pure water production can be accurately monitored in a continuous manner. Meanwhile, more research studies are needed to optimize the performance of hybrid systems so that the variable costs of water production from these systems can be further minimized. Definitely, the application of geothermal energy for desalination would eliminate thermal energy requirement from fossil fuels. However, the benefits of geothermal energy would also be felt if it is integrated with solar desalination plants because the storage of energy for desalination during periods of low or no solar irradiance would no longer be needed. Therefore, future investigations can be directed towards the design of desalination systems with integrated energy sources, in accordance with the peculiar energy requirements of the systems.

\section{Acknowledgements}

The authors would like to thank Masdar Institute of Science and Technology, Abu Dhabi, United Arab Emirates, for providing the platform where information on previous and current research on desalination systems powered by wind and geothermal energy was obtained.

\section{References}

1. Gude VG, Nirmalakhandan N, Deng S (2010) Renewable and sustainable approaches for desalination. Renew Sustain Energy Rev 14: 2641-2654.

2. Daer S, Kharraz J, Giwa A, Hasan SW (2015) Recent applications of nanomaterials in water desalination: A critical review and future opportunities. Desalination 367: 37-48.

3. Jamaly S, Darwish NN, Ahmed I, Hasan SW (2014) A short review on reverse osmosis pretreatment technologies. Desalination $354: 30-38$

4. Giwa A, Fath H, Hasan S (2015) Humidification dehumidification desalination process driven by photovoltaic thermal energy recovery (PV-HDH) for small scale sustainable water and power production. Desalination 377: 163-171.

5. Charcosset C (2009) A review of membrane processes and renewable energies for desalination. Desalination 245: 214-231.

6. He T, Yan L (2009) Application of alternative energy integration technology in seawater desalination. Desalination. 249: 104-108.

7. Akther N, Sodiq A, Giwa A, Daer S, Arafat HA, et al. (2015) Recent advancements in forward osmosis desalination: A review. Chem Eng J 281: 502-522.

8. Gude VG, Nirmalakhandan N, Deng S (2011) Desalination using solar energy Towards sustainability. Energy 36: 78-85.

9. Koutroulis E, Kolokotsa D (2010) Design optimization of desalination systems power-supplied by PV and W/G energy sources. Desalination 258: 171-181.

10. Jamaly S, Giwa A, Hasan SW (2015) Recent improvements in oily wastewater treatment: Progress, challenges, and future opportunities. J Environ Sci 37 $15-30$.

11. Giwa A, Hasan SW (2015) Theoretical investigation of the influence of operating conditions on the treatment performance of an electrically-induced membrane bioreactor. J Water Process Eng 6: 72-82.

12. Giwa A, Hasan SW (2015) Numerical modeling of an electrically enhanced membrane bioreactor (MBER) treating medium-strength wastewater. J Environ Manage 164: 1-9.

13. Hasan SW, Elektorowicz M, Oleszkiewicz JA (2012) Correlations between trans-membrane pressure (TMP) and sludge properties in submerged membrane electro-bioreactor (SMEBR) and conventional membrane bioreactor (MBR). Bioresour Technol 120: 199-205.

14. Giwa A, Ahmed I, Hasan SW (2015) Enhanced sludge properties and distribution study of sludge components in electrically-enhanced membrane bioreactor. J Environ Manage 159: 78-85.

15. Zeyoudi M, Altenaiji E, Ozer LY, Ahmed I, Yousef AF, et al. (2015) Impact of continuous and intermittent supply of electric field on the function and microbial community of wastewater treatment electro-bioreactors. Electrochim Acta.

16. Hasan SW, Elektorowicz M, Oleszkiewicz JA (2014) Start-up period investigation of pilot-scale submerged membrane electro-bioreactor (SMEBR) treating raw municipal wastewater. Chemosphere 97: 71-77.

17. Elektorowicz M, Hasan SW, Oleszkiewicz JA (2011) Pilot studies of a nove submerged membrane electro-bioreactor (SMEBR). Proc. Water Environ Fed WEFTEC

18. Eltawil M, Zhengming Z, Yang L (2008) Renewable energy powered desalination systems: Technologies and economics-State of the art. Twelfth Int Water Technol Conf. IWTC12, Alexandria, Egypt.

19. Bennett A (2011) Sustainable desalination: Renewable energy in desalination systems. Filtr + Seperation 48: 24-27

20. Heijman SGJ, Rabinovitch E, Bos F, Olthof N, van Dijk JC (2009) Sustainable seawater desalination: Stand-alone small scale windmill and reverse osmosis system. Desalination 248: 114-117.

21. Park GL, Schäfer Al, Richards BS (2011) Renewable energy powered membrane technology: The effect of wind speed fluctuations on the performance of a wind-powered membrane system for brackish water desalination. $\mathrm{J}$ Memb Sci 370: 34-44.

22. Subramani A, Badruzzaman M, Oppenheimer J, Jacangelo JG (2011) Energy minimization strategies and renewable energy utilization for desalination: a review. Water Res 45: 1907-1920.

23. Dehmas DA, Kherba N, Hacene FB, Merzouk NK, Merzouk M, et al. (2011) On the use of wind energy to power reverse osmosis desalination plant: A case study from Ténès (Algeria). Renew Sustain Energy Rev 15: 956-963.

24. Mbarga AA, Song L, Ross W, Williams K (2014) Rainwater, Integration of Renewable Energy Technologies With Desalination. Curr Sustain Energy Reports 1: 11-18.

25. Bourouni K (2012) Optimization of renewable energy systems: The case of 
Citation: Abusharkh AG, Giwa A, Hasan SW (2015) Wind and Geothermal Energy in Desalination: A Short Review on Progress and Sustainable Commercial Processes. Ind Eng Manage 4: 175. doi:10.4172/2169-0316.1000175

Page 5 of 5

desalination. Model Optim Renew Energy Syst, InTech.

26. Ma Q, Lu H (2011) Wind energy technologies integrated with desalination systems: Review and state-of-the-art. Desalination 277: 274-280.

27. Fadigas EAFA, Dias JR (2009) Desalination of water by reverse osmosis using gravitational potential energy and wind energy. Desalination 237: 140-146.

28. Ghaffour N, Bundschuh J, Mahmoudi H, Goosen MFA (2014) Renewable energy-driven desalination technologies: A comprehensive review on challenges and potential applications of integrated systems. Desalination 356: 94-114.

29. Gutiérrez H, Espíndola S (2010) Using low enthalpy geothermal resourcesto desalinate seawater and electrucity production in deser area in Mexico. GHC Bull.

30. Manenti F, Masi M, Santucci G, Manenti G (2013) Parametric simulation and economic assessment of a heat integrated geothermal desalination plant Desalination 317: 193-205. 